\title{
Coverage of G4-indicators in GRI-sustainability reports by electric utilities
}

\author{
Johannes Slacik and Dorothea Greiling \\ Faculty of Business and Economics, Institute of Management Accounting, \\ Johannes Kepler University Linz, Linz, Austria
}

\begin{abstract}
Purpose - Electric utility companies (EUC) are expected to play a key role toward implementing ambitious climate change aims being under critical scrutiny by regulators and stakeholders. However, EUC provide an under-researched field regarding sustainability reporting with the focus on economic, social and ecological concerns. This paper aims to gain insights of the sustainability reporting practice of EUC and the coverage of indicators based on the Global Reporting Initiative (GRI)-Guidelines.

Design/methodology/approach - A twofold documentary analysis of 186 GRI-G4 sustainability reports by EUC globally is conducted to investigate the coverage rates of G4-indicators. Neo-institutionalism and strategic stakeholder theory serve as theoretical lenses. A regression analysis is used to examine ownership, stockexchange listing, area of activity and region as potential drivers of sustainability reporting.

Findings - Results show that the coverage of indicators based on triple-bottom-line dimensions is moderate in EUC leaving room for improvement. The coverage of sector-specific indicators lacks behind the coverage of standard disclosure indicators. Results show that private and listed EUC show better coverage rates than public and not-listed EUC.

Research limitations/implications - Neo-institutionalism shows limited homogenization in the sector. Strategic stakeholder theory demonstrates insufficient stakeholder compliance of public and not-listed EUC. Originality/value - This study contributes to sustainability reporting research by focusing on the underresearched electricity sector. It provides practical reporting insights for EUC, the GRI and regulators.
\end{abstract}

Keywords Sustainability reporting, Electric utilities, Global reporting initiative, Regression analysis, Neoinstitutionalism, Strategic stakeholder theory

Paper type Research paper

\section{Motivation and research objectives}

Within the last decades and due to globalization, climate change, increasing environmental pollution and the scarcity of resources, companies experienced increased stakeholder pressure to disclose information not only on financial (economic) performance but also on ecological and social aspects (Boiral et al., 2019; Sartori et al., 2017; Garcia et al., 2016; Fernandez-Feijoo et al., 2014) along the Triple-Bottom-Line (TBL) dimensions (Elkington, 1997). As a reaction and to gain, maintain or regain legitimacy and reputation (Deegan, 2014), sustainability reporting is becoming an institutionalized practice, especially in private and stock-exchange listed companies (Traxler and Greiling, 2018; Brown et al., 2009). Studies show that the public and the non-profit sectors are lagging behind implementing and disclosing TBL-information in sustainability reports (SR) (Traxler and Greiling, 2018; Lock and Seele, 2016; Greiling et al., 2015a, b). This is contradictory to expectations that the public sector, as steward of public interests and welfare, should take a leading role when it comes to voluntary sustainability disclosures (Dumay et al., 2019; Traxler and Greiling, 2018).

(C) Johannes Slacik and Dorothea Greiling. Published by Emerald Publishing Limited. This article is published under the Creative Commons Attribution (CC BY 4.0) licence. Anyone may reproduce, distribute, translate and create derivative works of this article (for both commercial and non-commercial purposes), subject to full attribution to the original publication and authors. The full terms of this licence may be seen at http://creativecommons.org/licences/by/4.0/legalcode
GRI-

sustainability reports by electric utilities

Received 30 June 2019 Revised 15 November 2019 14 January 2020 18 February 2020 Accepted 18 February 2020 
JPBAFM 32,3

360
For improving, managing and standardizing SR, a plethora of globally, regional and national guidelines have been developed by standard setters of which the Global Reporting Initiative (GRI)-Guidelines are the most adopted by organizations worldwide (KPMG, 2017). More than 93\% of the top 250 largest companies worldwide published a SR in 2016-2017, whereby 74\% were using the GRI-G4-Guidelines (KPMG, 2017). The Guidelines provide besides a sector-neutral standard and specific disclosure guidelines also sector-specific supplements (GRI, 2015) allowing for a global perspective and comparison of reporting practices of most important industries worldwide (Lock and Seele, 2016).

This paper aims to gain insights on the sustainability reporting practice of Electric Utility Companies (EUC) and their coverage of indicators based on the GRI-Guidelines and its sectorspecific supplement. EUC with its mixed ownership present an industry which is especially confronted with sustainability issues and debates. For years the energy sector has undergone fundamental changes of market-liberalization increasing the hybridity in the sector, changing market conditions and deregulations, turning away from monopolistic companies (Erbach, 2016; Kerckhoffs and Wilde-Ramsing, 2010). EUC are perceived to be significant polluters contributing to climate change and environmental strain, showing social and ecological negative effects (CDP, 2017; GRI, 2015; Alrazi, 2014; Burgherr and Hirschberg, 2014; González González, 2010; Kerckhoffs and Wilde-Ramsing, 2010; Fischhoff, 2007). Critical stakeholders demand that EUC solve that problem (Ng and Nathwani, 2012) and focus on reducing negative environmental performance (Bahari et al., 2016; Moseñe et al., 2013). Hence, EUC are pressured to act sustainable but face a dilemma (González González, 2010). They are challenged to reduce environmental contamination by adapting to renewable energy and carbon-neutral technologies (Erbach, 2016; Moseñe et al., 2013; Bakhtina and Goudriaan, 2011) while simultaneously securing electricity supply (González González, 2010). The 2015 Paris Agreement and the UN Sustainability Development Goals commit national governments to combat climate change having direct effects on regulations and stakeholder expectations for the electricity sector (Traxler and Greiling, 2018). The sectors powerful economic and political influence and often the global operations of EUC are critically observed by stakeholders (Ng and Nathwani, 2012). Therefore, EUC are in need of extensive sustainability concepts, especially, since the sector has immense potential for contributing to TBL-developments while simultaneously being connected with negative social and environmental impacts (Kerckhoffs/Wilde-Ramsing, 2010). Stakeholders demand a TBLaccountability providing financial and non-financial information (Moseñe et al., 2013).

The credibility and reliability of SR have however been continuously criticized in literature for being a green-washing attempt, a legitimacy façade, for being non-transparent and limited in scope, implying impression management and marketing as disguise for enhancing a company's image (Lock and Seele, 2016; Cho et al., 2015). The negative image of EUC regarding sustainability engagement also increases skepticism among stakeholders (Miras-Rodríguez et al.,2015). Therefore, companies in environmental sensitive industries, likeEUC, are especially trying to increase their public reputation by disclosing voluntary non-financial reports (Fernandez-Feijoo et al., 2014; Moseñe et al., 2013). Talbot and Boiral (2018) criticize that impression management and marketing is often the disguise of SR for enhancing a company's image. A lack of complete, balanced, comparable, accurate, timely, clear and reliable SR decreases their credibility and relevance for stakeholders (Lock and Seele, 2016; Cho et al., 2015).

In perspective of that criticism, it is questionable whether SR by EUC cover the information needs of multiple stakeholders regarding TBL-accountability providing relevance for this study. This paper analyses the coverage of SR by EUC worldwide based on TBL-sustainability and the GRI-G4-Guidelines. Additionally, the paper analyzes dependency factors like ownership, stock-exchange listing, area of activity (national or international) and region and its influence on the coverage of SR. This gives opportunity to better understand the sustainability reporting practice of EUC and its influences. It provides 
practical reporting insights for EUC, standard-setters like the GRI and regulators and contributes to sustainability reporting research. Based on the research objective, the following research questions (RQs) are addressed:

$R Q 1$. How is the coverage of indicators in SR by EUC based on the GRI-G4-Guidelines and the three dimensions of sustainability?

$R Q 2$. Which factors influence the coverage of SR by EUC?

Thereafter, chapter two describes the theoretical approach. Chapter three illustrates the descriptive sample and methodology. Results of the study are presented in chapter four followed by the critical discussion, practical implications, limitations and future research in chapters five and six.

\section{Prior empirical studies and theoretical approach}

2.1 Prior studies on sustainability reporting by EUC

Prior literature between 2000 and 2018 showed that sustainability reporting of EUC has only been covered by research to a small and not generalizable extent. About 18 out of 22 articles found have been published since 2010 showing relevance of the topic. While 13 studies focus on environmental reporting, the three dimensions of sustainability are neglected. Ten articles focus on SR using the GRI-framework. Three studies focus on all three dimensions of sustainability and only four studies cover global SR (see Table 1).

Besides research on content and quality of SR, literature also investigated on dependency factors of sustainability reporting like ownership (Cormier and Gordon, 2001; Van der Laan Smith et al., 2005; Meyer and Pac, 2013; Bae, 2014), size (Cormier and Gordon, 2001; Alrazi et al., 2010, 2016), market situation and competition (Kraft, 2018), country/region and stakeholder pressure (Van der Laan Smith et al., 2005; Alrazi et al., 2010, 2016) as well as institutional contingencies (Moseñe et al.,2013) and whether or not these factors are influencing the coverage and quality of sustainability reporting. Additionally, Alrazi et al. (2016) identified that age, stock exchange listing and exposure to media are also influential factors for sustainability reporting. However, the authors are concentrating merely on environmental disclosure.

In sum it is noticed that SR by EUC are covering foremost environmental aspects while the social dimension is underrepresented. Only few studies analyze the coverage and the content of SR based on the TBL (see Gallego, 2006; Roca and Searcy, 2012; Sartori et al., 2017; Traxler and Greiling, 2018). While most studies take reference to the GRI-framework, research shows some limitations, namely, mostly small samples and the concentration on particular countries. Studies do not offer generalizable results. Furthermore, the literature review shows that only one study by Traxler and Greiling (2018) provides a larger sample of empirical research of EUC worldwide. However, since the GRI-G4 Guidelines are the currently most used, the study still presents a weak sample as the authors acknowledge.

\subsection{Neo-institutionalism (NI)}

NI can explain phenomena for this study since sustainability reporting is a reaction to institutional expectations which provoke companies to publish SR (Chen and Bouvain, 2009). While EUC were long institutionalized in the public sector, for the last decades they have undergone a transformation due to market liberalization. NI observes the reciprocal relationship between EUC and society/environment and the dynamic of a continuous building and reorganizing for adaptation of organizational structures. It is possible to analyze sustainability reporting insight of an organizational field like the energy sector and its sectorwide conformity to institutional expectations (Meyer and Rowan, 1977; DiMaggio and Powell, 1991; Boxenbaum and Jonsson, 2008; Chen and Roberts, 2010). If EUC comply with their organizational activities to established societal expectations (like norms, regulations, beliefs) 
JPBAFM 32,3

\section{2}

Cluster
Focus on environmental reporting
since environmental pollution of
EUC makes information exchange
with multiple stakeholders a central
importance. However, the three
dimensions of sustainability are
neglected

Focus on sustainability reports. Ten out of 19 articles use the GRIframework

Focus on all three dimensions of sustainability

Focus on single countries, especially the US and European countries

\section{Theories}

Stewardship theory, legitimacy theory, voluntary disclosure theory and signaling theory, impression management

Legitimacy theory, (strategic) stakeholder theory, contingency theory, neo-institutional theory, signaling theory, agency theory

Agency theory, strategic stakeholder theory, legitimacy theory

Legitimacy theory, stakeholder theory, contingency theory, neoinstitutional theory

Legitimacy theory, (strategic) stakeholder theory, signaling theory, agency theory, impression management
Authors

Freedman and Stagliano (2008); Alrazi et al. (2010); 2016; SilvaGao (2012); Chang (2013); Meyer and Pac (2013); Moseñe et al. (2013); Alrazi (2014); Camargos et al. (2014); Bae (2014); Bahari et al. (2016); Kraft (2018); Talbot and Boiral (2018)

Gallego (2006); Alrazi et al. (2010); 2016; Bakhtina and Goudriaan (2011); Roca and Searcy (2012); Moseñe et al. (2013); Alrazi (2014); Bahari et al. (2016); Garcia et al. (2016); Sartori et al. (2017); Kraft (2018); Traxler and Greiling (2018)

Gallego (2006); Ng and Nathwani (2012); Traxler and Greiling (2018)

Cormier and Gordon (2001); Van der Laan Smith et al. (2005); Gallego (2006); Freedman and Stagliano (2008); Roca and Searcy (2012); Silva-Gao (2012); Meyer and Pac (2013); Moseñe et al. (2013); Bae (2014) Alrazi et al. (2010); 2016; Kraft (2018); Talbot and Boiral (2018); Traxler and Greiling (2018)
Table 1.

Summary of the literature review
Five studies cover global sustainability reports, however, the sample size is small, except the study by Traxler and Greiling (2018)

EUC are able to secure access to resources, gain social support, maximize their legitimacy, reduce insecurities in the dynamic environment and secure organizational survival (DiMaggio and Powell, 1991; Chen and Roberts, 2010; Higgins and Larrinaga, 2014). In that regard, the theory targets the different institutional forces and processes established as coercive, normative and mimetic isomorphism (DiMaggio and Powell, 1991). NI also offers a theoretical base for identifying institutional drivers for sustainability reporting within a sector. Previous research recognized that isomorphic forces have thus the potential to influence the extent, quality and variety of disclosed information in SR (Moseñe et al., 2013; González González, 2010).

Coercive isomorphism is based on power relationships like political forces with sanctioning powers exerting formal or informal pressure (e.g. international, national or regional regulations demanding the adaption of ecological and societal responsibilities within a sector). The pressure can be felt as force (e.g. through the power of the European Commission, regulators, investors) (Chen and Roberts, 2010) or as firm inner conviction of a company. Cross-national guidelines and regulations like the EU-Directive or the Paris Agreement may however overarch institutional contingencies in the different countries (as seen in Europe; Moseñe et al., 2013) Also, stakeholder expectations toward adaptation of renewable energy, securing access to electricity and transparent information place pressure onto EUC (Moseñe et al., 2013; KPMG, 2017), whereby coercive isomorphism is developed 
(Boxenbaum and Jonsson, 2008). EUC are trying to avoid sanctioning and gain legitimacy by confirming to these expectations and regulations.

In comparison, normative isomorphism develops growing professionalism (DiMaggio and Powell, 1991) and standardization in industries (Bradford et al., 2016) through knowledge acquisition from education facilities or universities or through professional networks like the UN Global Compact (González González, 2010) which interact with companies teaching norms and regulations regarding organizational activities. The professionalized GRIframework, the UN Sustainability Development Goals and other guidelines are setting norms for reporting practice (KPMG, 2017). The GRI sector-specific supplements are also a contribution to the successful sector-wide institutionalization of standards (Brown et al., 2009). The EU-Directive already enforces the GRI-framework as standard. This puts normative pressure onto EUC which leads to homogenization within the sector. Normative isomorphism fosters a "how to" and "we have to disclose" attitude toward sustainability reporting and can be a stewardship attempt toward compliance with an occurring norm. In that case, compliance is a result of conventional business practices in accordance with established norms (Boxenbaum and Jonsson, 2008).

Mimetic isomorphism is a strategy to cope with those insecurities, like new regulations, extensive liberalization as well as the growing competition in the electricity sector, by imitating organizational structures and processes of other successful and legitimized EUC. For example, some studies identified the reporting practice of Spanish EUC as mimetic force for the rest of European countries (Moseñe et al., 2013; González González, 2010). While Contrafatto (2014) claims that mimetic isomorphism can bring sector-wide standardization regarding sustainability reporting, others tend to recognize a diffusion of isomorphic mechanisms (Shabana et al., 2017).

NI demonstrates that EUC homogenize because of isomorphic forces (Moseñe et al., 2013). A crucial factor for organizational survival is successful compliance to environmental and social pressures. However, complying with isomorphic pressures while acting upon efficiency targets is a phenomenon called decoupling from formal structures (Meyer and Rowan, 1977). By decoupling, companies can create stable situations staying within legitimized structures as symbolic conformity while actual activities may differ from such structures (Meyer and Rowan, 1977). While this strategy is described as defensive mechanism, recent studies see decoupling as part of an impression management (Boxenbaum and Jonsson, 2008). In that regard, it becomes questionable whether sustainability reporting is more than just a superficial conformity (Shabana et al., 2017; Cho et al., 2015).

In light of NI, isomorphic pressures have an impact on sustainability reporting. Coercive isomorphism may influence sustainability reporting of public and stock-exchange listed EUC due to regulations and societal expectations and the need for organizational and public legitimacy (Alrazi et al., 2016; Moseñe et al., 2013). Especially public EUC have a higher accountability obligation to their stakeholders. However, conflicting results in literature suggest that private and listed EUC disclose more indicators in SR by EUC (Traxler and Greiling, 2018; Meyer and Pac, 2013; Bae, 2014). Hence, the following hypotheses were established:

H1. Ownership influences the coverage in SR by EUC.

H2. Stock-exchange listing influences the coverage in SR by EUC.

Normative isomorphism may influence sustainability reporting of international public and listed EUC due to available voluntary standards, guidelines, memberships (e.g. UN Global Compact) suggesting appropriate reporting practices (González González, 2010). Hence, the area of activity may also influence SR by EUC to sustain international reputation.

H3. Area of activity influences the coverage in SR by EUC. 
JPBAFM 32,3

\section{4}

Mimetic isomorphism may also influence sustainability reporting of EUC from economically weaker countries (regions) to gain international business legitimacy (Alrazi et al., 2016; Moseñe et al., 2013). International Public, Private and listed EUC are trying to adopt good reporting practices from other more legitimate EUC in order to meet international standards and stakeholder expectations.

H4. Region influences the coverage in SR by EUC.

\subsection{Strategic stakeholder theory}

Strategic stakeholder theory focuses on the relationship between an organization and the variety of strategic relevant stakeholder groups. By taking stakeholder needs and their demands into account, companies ideally meet stakeholders' expectations securing the availability of resources while creating value for stakeholders (Loh et al., 2015; Hörisch et al., 2014; Harrison, 2013; Freeman, 2010). The study by Van der Laan Smith et al. (2005) shows that EUC encounter a great variety of stakeholders like shareholders, customers, regulators, environmental activists, employees, politicians and society with partly conflicting expectations. EUC are faced with the challenge to balance divergent interests, information needs and transparency demands of multiple stakeholders (Garcia et al., 2016; Bahari et al., 2016; Bonsón and Bednárová, 2015; Chen and Roberts, 2010; Freeman, 2010). While the interests of the various stakeholders should be considered alike (Roca and Searcy, 2012) practice shows that stakeholders of EUC are not given equal relevance. Deegan (2000) categorizes stakeholder theory into an ethical and managerial branch which can be compared to Wilmhurst's (2004) normative and managerial perspectives. The ethical branch or normative perspective is to focus on all stakeholders equally. Managers, however, ascribe more relevance to expectations of strategically more interesting stakeholder groups if they consider them to be powerful, foster ways of legitimacy or present certain urgencies and dependencies (Islam and Deegan, 2008; Van der Laan Smith, et al., 2005; Deegan, 2000; Frooman, 1999; Mitchell et al., 1997) thus leading to different organizational strategies of interaction (Herremans et al., 2016). The more dependent organizations are on stakeholders the more likely will managers disclose information necessary for those relevant stakeholders (Frooman, 1999). With the focus on sustainability reporting, this study thus addresses stakeholder theory in light of a managerial perspective.

As a strategic communication tool to relevant stakeholders, EUC are publishing SR trying to match stakeholder expectations and information needs (Loh et al., 2015; Van der Laan Smith et al., 2005; Wilmhurst, 2004) by addressing TBL-accountability issues (Kaur and Lodhia, 2018). Hence, strategic stakeholder theory is an important theory to better understand sustainability reporting practices (Roca and Searcy, 2012; Guthrie et al., 2004). It also helps to explain that sustainability reporting may be influenced by the focus on relevant or selective stakeholders, thus disclosing only selective information.

H5. The selection of relevant stakeholders influences SR by EUC.

\section{Sample description and methodology}

\subsection{Analysis of the coverage of SR}

This research focuses on identifying the quantitative coverage of indicators in SR by EUC by analyzing SR content based on the GRI-G4-framework (RQ1). G4-Guidelines are the latest version of GRI-Guidelines after G3.1 and before the GRI-Standard was developed. The G4Guidelines currently offer the most uploaded reports. For this research, 489 energy companies were retrieved from the GRI database (deadline: 31.12.2017). 186 latest GRI-G4 SR by EUC worldwide were included for further analysis. The other 303 hits were either reports 
in the oil or gas sector or had no G4-reporting or were only available in other languages than English or German and were thus excluded from our sample. Due to the foremost voluntary nature of sustainability reporting, the 186 latest SR included reports from 2013 up to 2017, most of which were from SR published in 2016. This sample presents thus the most current status of the reporting practice of the electricity sector. Compared with the previous study by Traxler and Greiling (2018), this study simultaneously shows the learning-curve of discloser practice. However, a comparability problem of, e.g., national, regional or cultural influences did not exist since this study investigated quantitatively measured indicators based on the GRI-content-index and not the qualitative information of disclosed data. EUC are able to report on all GRI provided indicators no matter the national or regional situation.

Indicators and its coverage in SR by EUC were then analyzed twofold: firstly, with a quantitative content analysis of G4-indicators of 186 SR identifying the (total) coverage rates ((T)CR) of reported indicators; secondly, with a multiple (backward) regression analysis for identifying differences between dependency-factors and TCR (RQ2). The coverage of indicators was analyzed by taking the GRI-content-index in each SR, which provides a list of information and indicators to be covered making SR comparable and allows for deriving a deductive category-system to systematically analyze and evaluate information to be covered in SR. This study analyzed all disclosed general standard and specific and sector-specific G4indicators of EUC including all performance indicators $(\mathrm{PI})$, material aspects and disclosures on management approach (DMA) that "provides narrative information on how an organization identifies, analyzes, and responds to its actual and potential material economic, environmental and social impacts" (GRI, 2015, pp. 45).

The category-system finally covers seven subcategories: (1) 63 general standard disclosures; (2) 21 economic; (3) 47 ecological; and 91 social indicators, namely: (4) 27 to labor practice and decent work; (5) 22 to human rights; (6) 20 to society and (7) 22 to product responsibility. Altogether, the category-system consists of 222 indicators for EUC listed in each content-index with reference to pages in SR and is base for the analysis (random checks were performed whether indicators are also covered in SR-texts). To assess the CR of indicators, a binary coding-scale was used: 1 - when EUC disclosed an indicator and 0 - when they did not. A partial disclosure of indicators as well as declared reasoning for nondisclosure was also treated as disclosed (see GRI, 2015). Therefore, it is also possible for EUC with restricted fields of activities to reach an extensive CR. Not explaining the non-disclosure of indicators including its DMA was however treated as non-disclosed for lack of transparent communication. The TCR for all seven subcategories were then analyzed in SPSS. The calculations were done by dividing the number of disclosed indicators by the number of total indicators of each subcategory (i.e. the economic dimension consists of 21 indicators, of which company A discloses ten indicators - resulting in a CR of the economic subcategory of $47.6 \%$ (10/21)). Furthermore, the TCR was calculated taking the number of indicators as base giving all indicators the same relevance.

$$
\mathrm{TCR}=\frac{\sum \text { Amount of disclosed indicators }}{222}
$$

\subsection{Analysis of dependency factors}

Based on the TCR as dependency variable, possible determinants influencing SR like ownership, stock-exchange listing, area of activity and region were analyzed (RQ2). Each factor was tested in SPSS for influencing the TCR. For each factor a $\mathrm{H}_{0}$-hypothesis (no correlation) and $\mathrm{H}_{1}$-hypothesis (positive correlation) with $\alpha=0.05$ were assigned. $\mathrm{H}_{0}$ was rejected if the $p$-value was below alpha $=0.05$. Hypotheses are established for ownership, stock-exchange listing, nationality and region (see hypotheses development in Section II) each coded with 0 or 
JPBAFM 32,3

366
1 (Mann-Whitney-U-test) and 1-8 for regions (Kruskal-Wallis-H-Test). Ownership defined whether EUC were more in private (0) or in public (1) hands ( $>50 \%$ of shares). Stock-exchange listing shows whether EUC are listed (1) or not (0). Area of activity shows whether EUC are only national (0) or international active (1). The region is separated into eight areas since regional culture, economies or laws may influence SR: Africa (1), Asia (2), Central America including the Caribbean (3), European Union and Eastern Europe (4), Middle East (5), North America (6), Oceania (7), South America (8).

Additionally, the multiple (backward) regression analysis shows the interrelation of factors in regard to the TCR. It also serves as an instrument of reliability regarding the results of the other two tests.

\section{Results}

\subsection{Descriptive results}

This empirical study analyzed 186 GRI-G4 SR by EUC from 2013 to 2017, most of which were published in the year 2016 . Results show that a bit less than $78 \%$ of all SR cover sectorspecific indicators for electric utilities which are on average only covered to $42.6 \%$. While EUC of 45 countries publish G4-SR, most SR are published in the USA, Brazil, Germany, Spain and Russia accounting for $38.7 \%$ of the entire sample. $60 \%$ of all SR are from public EUC. $59.6 \%$ are internationally active while $68.8 \%$ are stock-exchange listed EUC. Furthermore, results show $46.7 \%$ of SR are published in Europe presenting the largest sample while Central America, Africa and Oceania show the least published SR (see Figure 1).

\subsection{Results of the coverage of SR}

Regarding RQ1, the following CR along all seven subcategories and the three dimensions of sustainability were found: While general standard disclosures are covered to $74.6 \%$, all other categories except labor practice and decent work cover less the $50 \%$ of indicators. The least amount of information is provided in the subcategories human rights and product responsibility. Figure 2 shows the six TBL-subcategories. Appendix 1 provides further explanations of highest and lowest $\mathrm{CR}$.

Figure 3 presents a final summary of results. A comparison of $\mathrm{CR}$ shows that information on DMAs are much less reported than its related PI. Results also show that the coverage of European SR almost matches the coverage of SR worldwide despite the dominant reporting role of Europe. Moreover, the TCR of SR by EUC worldwide is illustrated. It shows that $50.5 \%$

\begin{tabular}{lclclc} 
Country & AmountCountry & AmountCountry & Amount \\
\hline USA & 16 & Japan & 5 & Irland & 1 \\
\hline Brazil & 14 & Poland & 4 & Lithuania & 1 \\
\hline Germany & 12 & Netherlands & 4 & Hungary & 1 \\
\hline Spain & 11 & Columbia & 4 & Slowenia & 1 \\
\hline Russia & 11 & Norway & 3 & Sweden & 1 \\
\hline Italy & 8 & Turkey & 3 & Chile & 1 \\
\hline Canada & 7 & Greece & 3 & Peru & 1 \\
\hline Austrailia & 7 & Philipines & 3 & Saudi Arabia & 1 \\
\hline South Korea & 7 & Indonesia & 3 & Vietnam & 1 \\
\hline Switzerland & 6 & Portugal & 2 & Macao & 1 \\
\hline Austria & 6 & Belgium & 2 & UAE & 1 \\
\hline Finland & 6 & New Zeeland & 2 & South Africa & 1 \\
\hline India & 6 & Nigeria & 2 & Oman & 1 \\
\hline China & 6 & Qatar & 2 & Mauritius & 1 \\
\hline Thailand & 5 & Czech Republic & 1 & Singapore & 1 \\
\hline$\sum$ & & & & & 186 \\
\end{tabular}

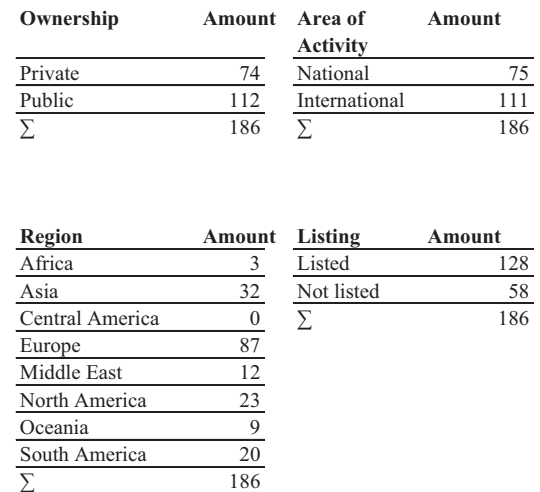

$\sum$
Figure 1.

Amount of SR based on dependency factors 

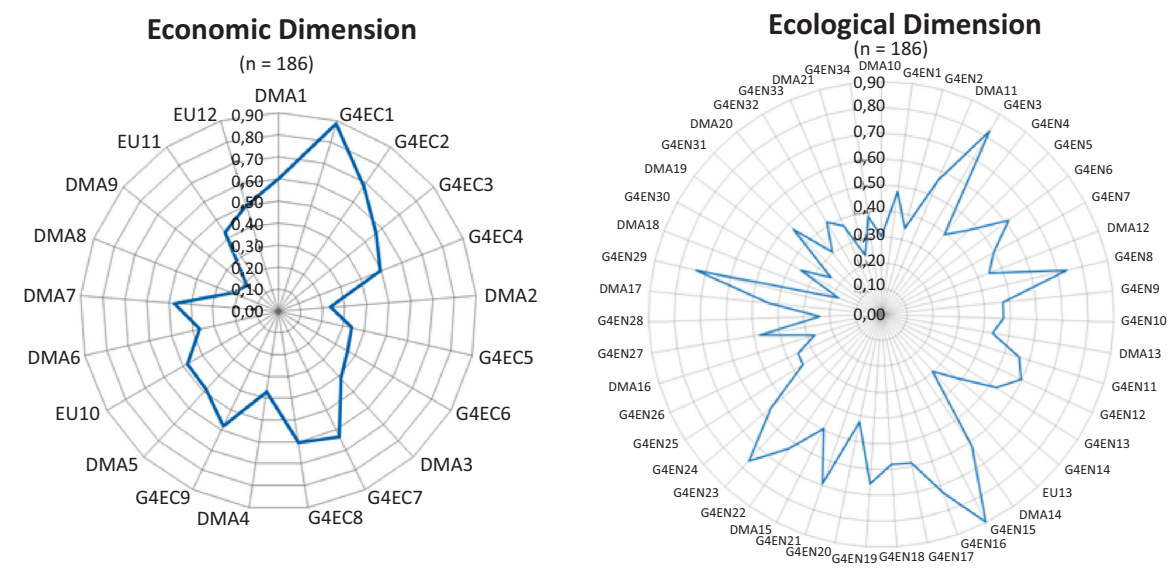

Social Dimension Labor practice and decent work

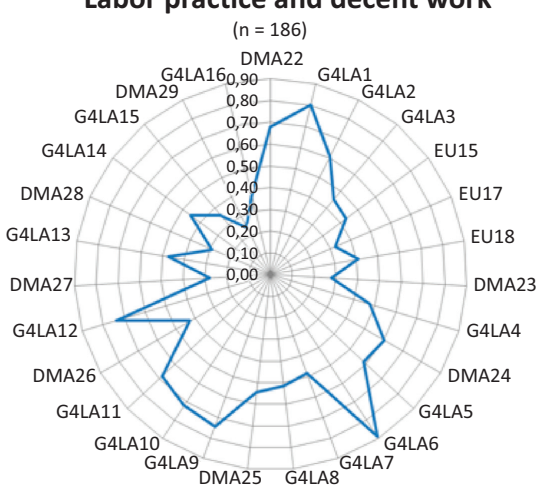

Social Dimension Society

( $n=186$ )

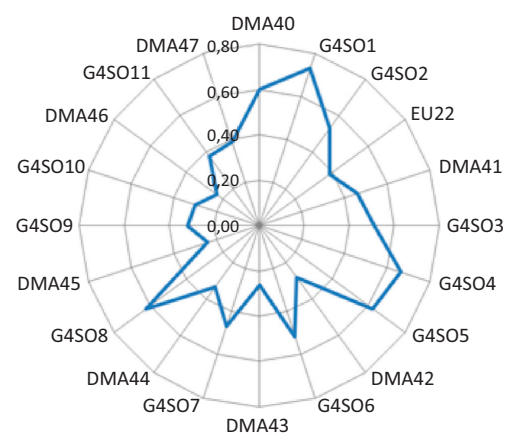

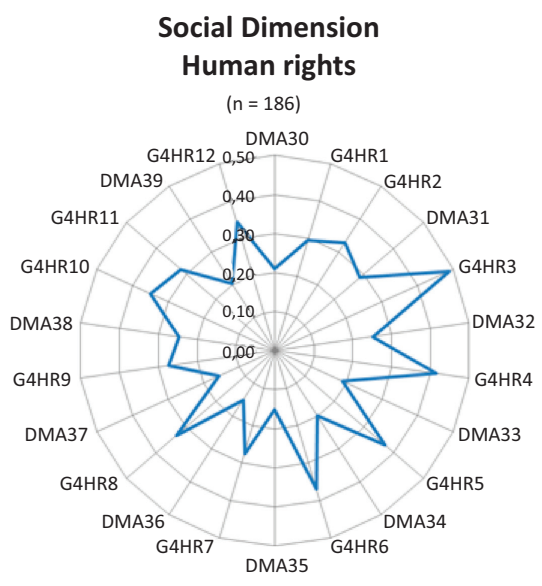

Social Dimension Product responsibility

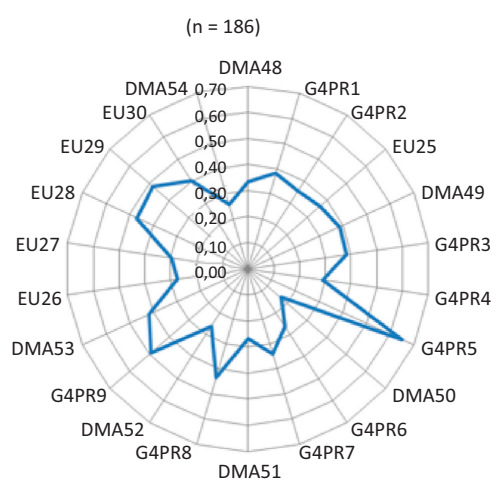

GRI-

sustainability reports by electric utilities

367
Figure 2. CR of the TBLdimension 

32,3

368
JPBAFM

(94/186) of all GRI-G4 SR report less than $50 \%$ of indicators. Some of the EUC barely cover $15 \%$ of all indicators. However, 30 of 186 EUC cover more than $75 \%$ in SR. None of the three dimensions of sustainability are covered beyond $48.7 \%$. The ecological dimension shows the highest coverage, followed by the economic and the social dimension.

\subsection{Results of dependency factors}

Table 2 displays how dependency factors like ownership, stock-exchange listing, area of activity and region influence the coverage of SR by EUC (RQ2).

In relation to ownership, results show that $74 \mathrm{EUC}$ are privately owned disclosing $56.5 \%$ of indicators on average, while 112 public EUC cover only $49.8 \%$ with a significance of $p=0.022$. The TCR of stock-exchange listed EUC (54.9\%) is almost $8 \%$ points higher than the TCR of not-listed EUC (47.2\%) with a significance of $p=0.021 .69 \mathrm{EUC}$ are public and stock listed while only 59 EUC are private and stock listed. The higher TCR of private and stock listed EUC shows significant results $(p=0.017)$ as does the lower TCR of public and not-listed $\operatorname{EUC}(\phi=0.011)$. The regression analysis verifies these results $(\phi=0.015)$ showing reliability. Area of activity shows no significance. Non-significant results were also found when evaluating the region $(p=0.787)$.

However, the backward-regression analysis shows that particularly private and listed Asian EUC show significantly better coverage in SR than any other region $(\phi=0.037)$. This also shows that public and not-listed Asian EUC cover SR-content significantly lower (see Table 2).

\section{Discussion and conclusions}

Concerning RQ1, the results show that sustainability reporting and the disclosure on sustainability performance is only slowly becoming an institutionalized business practice in EUC. While general standard disclosures regarding company profile are on average well

\begin{tabular}{|l|l|l|l|}
\hline Subcategories & CR Global & CR DMA & CR PI \\
\hline General Standard Disclosures & $74.6 \%$ & -- & -- \\
\hline Economic Disclosures & $47.0 \%$ & $37.3 \%$ & $54.6 \%$ \\
\hline Ecologic Disclosures & $48.7 \%$ & $37.7 \%$ & $52.4 \%$ \\
\hline Labor Practice and Decent Work & $50.9 \%$ & $41.7 \%$ & $55.3 \%$ \\
\hline Human Rights & $28.2 \%$ & $20.4 \%$ & $34.7 \%$ \\
\hline Society & $44.2 \%$ & $35.0 \%$ & $50.4 \%$ \\
\hline Product Responsibility & $36.3 \%$ & $30.0 \%$ & $39.2 \%$ \\
\hline
\end{tabular}

Figure 3.

CR and TCR of SR by EUC and the three dimensions of sustainability

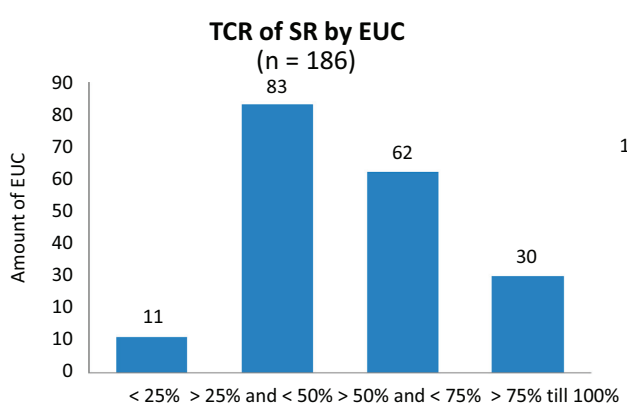

3 Dimensions of Sustainability by EUC ( $n=186)$

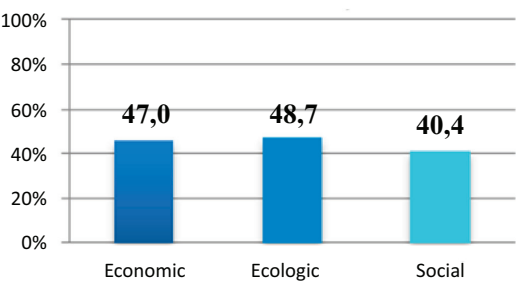




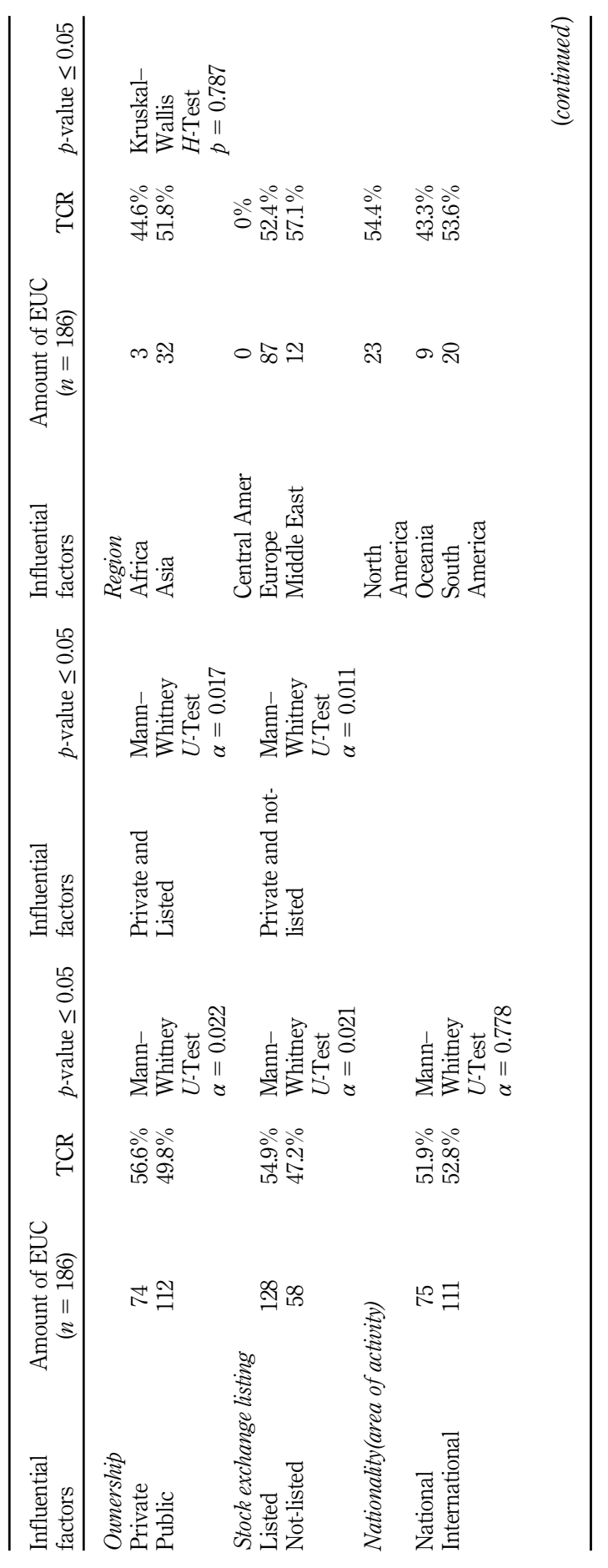

GRIsustainability reports by electric utilities

369

Table 2. Influence of dependency factors of SR 


\begin{tabular}{l} 
JPBAFM \\
32,3 \\
$\mathbf{3 7 0}$ \\
\hline
\end{tabular}

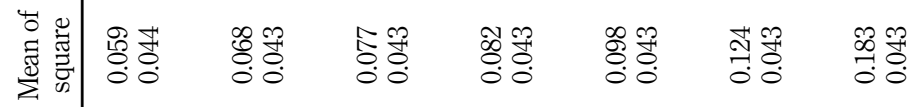

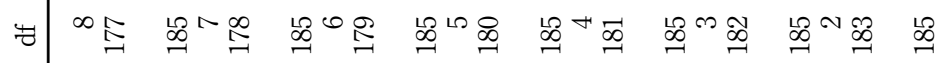

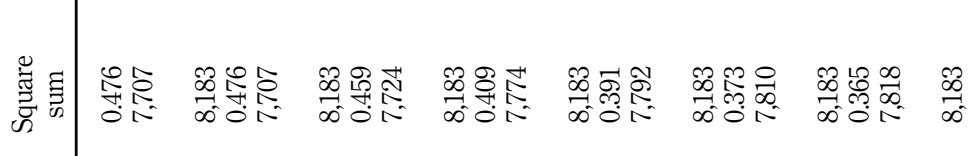

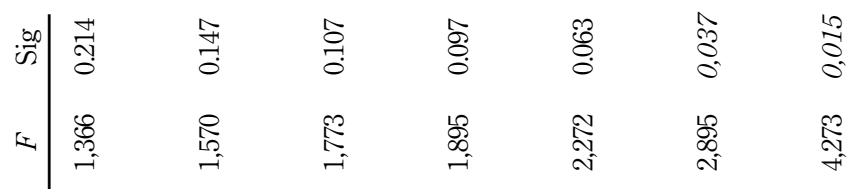

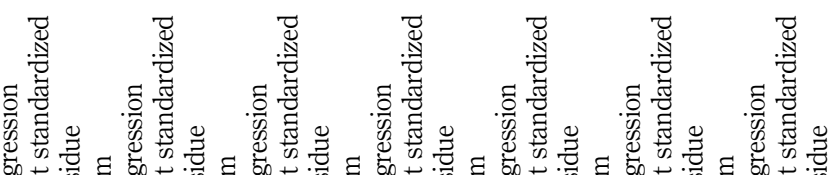

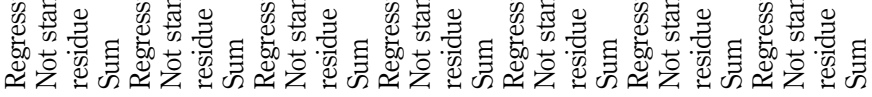

营

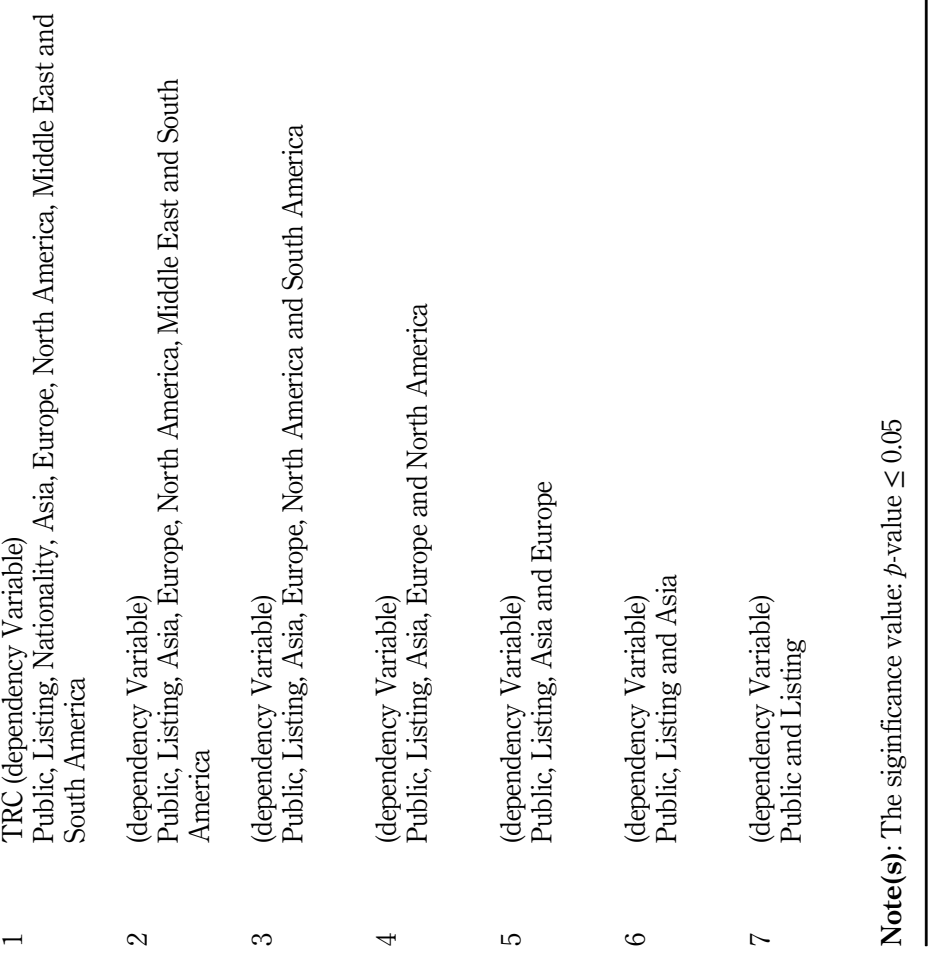

Table 2. 
covered, ecological, social and even economic TCR are imbalanced showing room for improvement. In particular, the social dimension is still underrepresented in SR by EUC. With $42.6 \%$, the average CR of sector-specific indicators is even weaker, which raises the question how well EUC meet reporting expectations of regulators, standard-setters and other critical stakeholders. The extend on which EUC report on TBL-issues is influenced by two dependency factors, namely ownership and stock-exchange listing, especially in Asian EUC (RQ2). Non-significant results of the area of activity and all other regions are probably due to cross-national regulations, like the EU-Directive or the Paris Agreement suggesting a crossnational homogenization of SR. Results can be further interpreted in light of the theoretical lenses:

\subsection{Neo-institutionalism}

EUC are subjected to institutional forces like regulations, societal pressure and stakeholder demands as part of a coercive isomorphism. In exchange for critical resources, medium and highly salient stakeholder put pressure onto EUC demanding extensive accountability and transparency (Kaur and Lodhia, 2018) driving especially private and stock-exchange listed EUC toward higher coverage in SR. Listed EUC disclose more information than not-listed EUC. Public EUC lag behind regarding the quantitative TCR despite the much earlier confrontation with critical stakeholders and the much more complex public accountability obligations than their private sector counterparts (see Bae, 2014). Public EUC seem to feel complacent lacking of political control mechanisms.

Considering that GRI is a voluntary standard and therefore unlike the energy sector regulation a "privatization of governance" (Gibassier, 2015), the higher guideline compliance of private and listed EUC can be interpreted that they are more inclined toward private governance modes. Such behavior can be seen in line with normative isomorphism or a higher degree of adoption of voluntary professional practices to oblige to the institutionalized norm of TBL-reporting.

Looking at the coverage of indicators, only some indicators are fairly consistent covered, while others vary considerably. The cross-national concentration on the disclosure of similar TBL-indicators in SR by EUC like economic performance, emission, energy and employment is a result of mimetic isomorphism (see also Moseñe et al., 2013) and what can be regarded as a tendency of selected homogenization. EUC are trying to gain national and international image and sympathy providing transparent SR by imitating reporting practices from other legitimized EUC (Bonsón and Bednárová, 2015; Fernandez-Feijoo et al., 2014; Moseñe et al., 2013).

However, traditional NI authors would interpret the idea of a selective homogenization as a sign of decoupling or impression management (Boxenbaum and Jonsson, 2008) for enhancing a company's reputation, being nothing more than superficial conformity to stakeholder demands (Shabana et al., 2017; Cho et al., 2015). It allows, however, for assuming that despite coercive, mimetic and normative forces, a sector-wide homogenization is so far limited.

In light of NI, the observed higher total compliance rate of private and listed $\mathrm{EUC}$ is not only in line with prior findings across sectors but can also be interpreted as a higher adaptability toward isomorphic pressures. Private governance modes like the GRI may face lesser acceptance resistance in private and listed EUC which are well aware of the advantages of reputational signaling.

A more positive interpretation of the mediocre TCR could be that EUC might concentrate their reporting on stakeholder-material aspects. The G4-Guidelines recommend concentrating SR on aspects which stakeholders regard as highly relevant. To clarify this, the reported indicators need to be matched with the materially matrices of EUC. In the case of public EUC, the low compliance rates could also be due to the dense net of mandatory public accountability 
JPBAFM 32,3 obligations (e.g. in form of democratic or political accountability or special scrutiny by the court of audits). The reporting fatigue (Gibassier, 2015) may be higher in public EUC as they are more densely regulated.

\subsection{Strategic stakeholder theory}

EUC encounter a variety of stakeholders with different information needs and a potential for conflicting interests (Moseñe $e t$ al., 2013). As a managerial reaction to the institutionalized stakeholder-power of relevant (critical) stakeholders (Deegan, 2000), one rational strategy to meet extensive accountability and transparency demands can be to report as many indicators as possible thereby increasing reputation and stakeholder value (Hörisch et al., 2014). The mediocre TCR of EUC shows, however, that EUC do not pursue this approach and refrain of potentially overloading stakeholders with too many indicators. The purpose and publication of SR as tool for communicating to stakeholders is not used appropriately, so far, and does not seem to be particularly stakeholder-oriented. Public EUC miss especially the opportunity of stakeholder value and image creation by complying with stakeholder information needs through transparent, credible and reliable reporting. It appears that public EUC are less dependent on relevant stakeholders.

The mediocre TCR show that no particular stakeholder group of EUC appears relevant except for employees - who surely create dependencies. Employment as part of the social dimension is covered slightly higher than the economical or the ecological dimension and indicates the relevance of employees. However, DMAs for those indicators remain underdisclosed. It may be hard for employees (and other interested stakeholders) to trust SR and attribute value to EUC if apparently relevant aspects and its DMAs are not covered satisfactorily. The stakeholder-power of employees seems to evoke a decoupling toward impression management. In general, it appears that stakeholders may not be as salient as they are expected to be.

Furthermore, the higher TCR of private and listed EUC allows for assuming that they are more stakeholder-oriented than public and not-listed EUC. This is contradictory to the expectations that public utilities as stewards of society at large are intrinsically stakeholderoriented. However, especially public and not-listed Asian EUC seem to deemphasize with their stakeholders. While private and listed Asian EUC better comply with regulations and stakeholder information needs. Thus, it can be assumed that the continuous privatization of the sector is globally beneficial to stakeholders and their attribution of organizational and public value.

The overall purpose of EUC publishing SR does not seem clear to relevant stakeholders. Therefore, the intention and message may be misunderstood by stakeholders who may have difficulty trusting disclosed information (Dumay et al., 2019), especially by public and notlisted EUC. Whether or not disclosed sustainability information is part of an open and honest disclosure or an act of impression management or a green-washing attempt makes a difference (Bartels et al., 2016).

In light of strategic stakeholder theory, the lack of stakeholder compliance in SR by EUC may increase devaluation (being understood as decoupling) from an expected reporting practice. Under stakeholder accountability aspects, private and listed but especially public and not-listed EUC still have room to improve the use of SR as a communication tool for demonstrating their extent of stakeholder value creation through transparent, credible and reliable reporting.

\subsection{Practical implications and contributions}

Consequently, governments and regulators should increase and heighten their coercive pressure in those areas which they regard as essential for monitoring the sustainability 
performance of the EUC. This would eventually lead to homogenization in the sector and a better reporting practice of EUC. Currently the frequently reported indicators are not sectorspecific enough.

Standard-setters like the GRI should continue to urge EUC to focus on materiality identifying stakeholder-material aspects in SR. The GRI-G4 sector supplement is obviously not regarded as useful tool for improving stakeholder accountability as the average TCR of the sector-specific indicators is even lower than the coverage of sector neutral indicators. Identified results could be a starting point for optimizing the GRI-framework toward improved stakeholder accountability in the electricity sector. The disclosure should be finetuned toward stakeholder-relevant aspects.

Furthermore, EUC are asked to adapt a more pro-active stewardship attitude toward sustainability performance and transparent reporting, acting as stewards to its environment and society. This may produce more credible and reliable reports and will help gaining back trust of critical stakeholders. Based on this study, however, trusting that isomorphism will improve and homogenize the reporting practices of EUC is a misleading assumption. EUC can improve their reporting practices by focusing on quality disclosure of materiality and assuring a complete coverage of those identified material aspects. However, sustainability performance is not a matter of disclosing indicators but rather a matter of adapting performance to continuously improve on all material TBL-aspects.

This study contributes to the, so far, under-researched field of sustainability reporting practices of EUC which are in an important sector under climate change and infrastructure aspects. This study presents findings of a global comparison of SR by EUC along the TBLdimensions offering a more holistic picture of the sustainability reporting practice of EUC. In addition, the theoretical background allowed for identifying a selective homogenization of disclosed indicators in SR by EUC and a lack of stakeholder compliance.

\subsection{Limitations and future research}

This study has limitations since only the quantitative CR of GRI-G4 reports by EUC were analyzed. The quality of disclosed information and the actual sustainability performance of EUC was not investigated which offers avenues for further research. Future research could also focus on other reporting frameworks, scrutinizing stakeholder engagement and compliance to their information needs. Furthermore, it is still open to what extent EUC should disclose relevant aspects, i.e. climate change indicators. Whether a change towards a stewardship perspective would improve the reporting practices or whether the reporting fatigue of public utilities is caused by an accountability overload elsewhere is also something to be further explored.

\section{References}

Alrazi, B. (2014), "The carbon disclosure of the Malaysian major power producers: an exploratory study", Journal of Business Management, Vol. 3 No. 2, pp. 12-25.

Alrazi, B., De Villiers, C. and Van Staden, C. (2010), "The environmental reporting of electric utilities: an international comparison", [online], Research Paper submitted to the 9th CSEAR Australasian Conference, Albury Wodonga, Australia, available at: https://www.researchgate.net/publication/ 229027653_The_Environmental_Reporting_of_Electric_Utilities_an_International_Comparison (accessed 6 December 2017).

Alrazi, B., De Villiers, C. and Van Staden, C. (2016), "The environmental disclosures of the electricity generation industry: a global perspective", Accounting and Business Research, Vol. 46 No. 6, pp. 665-701.

Bae, H. (2014), "Voluntary disclosure of environmental performance: do publicly and privately owned organizations face different incentives/disincentives?", American Review of Public Administration, Vol. 44 No. 4, pp. 459-476. 
JPBAFM 32,3

Bahari, N.A.S., Alrazi, B. and Husin, N.M. (2016), "A comparative analysis of carbon reporting by electricity generating companies in China, India, and Japan", Procedia Economics and Finance, Vol. 35, pp. 74-81.

Bakhtina, K. and Goudriaan, J.W. (2011), "CSR reporting in multinational energy companies", European Review of Labour and Research, Vol. 17 No. 1, pp. 95-99.

Bartels, W., Fogelberg, T., Hoballah, A. and van der Lugt, C.T. (2016), Carrots Sticks: Global Trends in Sustainability Reporting Regulation and Policy”, KPMG; Global Reporting Initiative (GRI), United Nations Environment Programme; Centre for Corporate Governance in South Africa, Amsterdam.

Boiral, O., Heras-Saizarbitoria, I. and Brotherton, M.C. (2019), "Assessing and improving the quality of sustainability reports: the auditors' perspective", Journal of Business Ethics, Vol. 155 No. 3, pp. 703-721.

Bonsón, E. and Bednárová, M. (2015), "CSR reporting practices of Eurozone companies”, Revista de Contabilidad - Spanish Accounting Review, Vol. 18 No. 2, pp. 182-193.

Boxenbaum, E. and Jonsson, S. (2008), "Isomorphism, diffusion and decoupling", in Greenwood, R., Oliver, C., Lawrence, T.B. and Meyer, R.E. (Eds), The SAGE Handbook of Organizational Institutionalism, Sage Publications, London, pp. 78-99.

Bradford, M., Earp, J.B., Showalter, D.S. and Williams, P.F. (2016), "Corporate sustainability reporting and stakeholder concerns: is There a disconnect?", Accounting Horizons, Vol. 31 No. 1, pp. 83-102.

Brown, H.S., De Jong, M. and Levy, D.L. (2009), "Building institutions based on information disclosure: lessons from GRI's sustainability reporting”, Journal of Cleaner Production, Vol. 17 No. 6, pp. 571-580.

Burgherr, P. and Hirschberg, S. (2014), "Comparative risk assessment of severe accidents in the energy sector", Energy Policy, Vol. 74, pp. 45-S56.

Camargos, M.R., Jannuzzi, G.M. and Gavira, M.O. (2014), "Analysis of the sustainability reporting initiatives of electric utilities in Brazil", Industrija, Vol. 42 No. 1, pp. 127-147.

CDP (2017), "Charged or static: which European electric utilities are prepared for a low carbon transition? Executive summary", London, available at: https://www.cdp.net/fr/investor/sectorresearch/electric-utilities-report (accessed 23 July 2018).

Chang, K. (2013), "The effects of ownership and capital structure on environmental information disclosure: empirical evidence from Chinese listed electric firms", WSEAS Transactions on Systems, Vol. 12 No. 12, pp. 637-649.

Chen, S. and Bouvain, P. (2009), "Is corporate responsibility converging? A comparison of corporate responsibility reporting in the USA, UK, Australia, and Germany", Journal of Business Ethics, Vol. 87, Supplement 1, pp. 299-317.

Chen, J.C. and Roberts, R.W. (2010), "Toward a more coherent understanding of the organizationsociety relationship: a theoretical consideration for social and environmental accounting research”, Journal of Business Ethics, Vol. 97 No. 4, pp. 651-665.

Cho, C.H., Laine, M., Roberts, R.W. and Rodrigue, M. (2015), "Organized hypocrite, organizational façades, and sustainability reporting”, Accounting, Organizations and Society, Vol. 40, pp. 78-94.

Contrafatto, M. (2014), "The institutionalization of social and environmental reporting: an Italian narrative", Accounting, Organizations and Society, Vol. 39 No. 6, pp. 414-432.

Cormier, D. and Gordon, I.M. (2001), "An examination of social and environmental reporting strategies", Accounting, Auditing and Accountability Journal, Vol. 14 No. 5, pp. 587-617.

Deegan, C. (2000), Financial Accounting Theory, McGraw-Hill Book Company, Sydney.

Deegan, C. (2014), "An Overview of legitimacy theory as applied within the social and environmental accounting literature", in Bebbington, J., Unerman, J. and O'Dwyer, B. (Eds), Sustainability Accounting and Accountability, $2^{\text {nd }}$ ed., Milton Park and NY, pp. 248-272.

DiMaggio, P.J. and Powell, W.W. (1991), "The iron cage revisited: institutional isomorphism and collective rationality", in Powell, W.W. and DiMaggio, P.J. (Eds), The New Institutionalism in Organizational Analysis, University of Chicago Press, Chicago and London, pp. 63-82. 
Dumay, J., La Torre, M. and Farneti, F. (2019), "Developing trust through stewardship: implications for intellectual capital, integrated reporting, and the EU Directive 2014/95/EU", Journal of Intellectual Capital, Vol. 20 No. 1, pp. 11-39.

Elkington, J. (1997), Cannibals with Forks, The Triple Bottom Line of 21st Century Business, Capstone, Oxford.

GRI-

sustainability reports by

electric utilities

Erbach, G. (2016), "Understanding electricity markets in the EU”, [online], Briefing November 2016, available at: http:/www.europarl.europa.eu/RegData/etudes/BRIE/2016/593519/EPRS_BRI(2016) 593519_EN.pdf (accessed 10 November 2017).

Fernandez-Feijoo, B., Romero, S. and Ruiz, S. (2014), "Commitment to Corporate social responsibility measured through global reporting initiative reporting: factors affecting the behavior of companies", Journal of Cleaner Production, Vol. 81, pp. 244-254.

Fischhoff, M.E. (2007), "Electricity company managers' views of environmental issues: implications for environmental groups and government", Energy Policy, Vol. 35 No. 7, pp. 3868-3878.

Freedman, M. and Stagliano, A.J. (2008), "Environmental disclosures: electric utilities and phase 2 of the clean air act", Critical Perspectives on Accounting, Vol. 19 No. 4, pp. 466-486.

Freeman, R.E. (2010), Stakeholder Theory: The State of the Art, Cambridge University Press, Cambridge.

Frooman, J. (1999), "Stakeholder influence strategies", Academy of Management Review, Vol. 24 No. 2, pp. 191-205.

Gallego, I. (2006), "The use of economic, social and environmental indicators as a measure of sustainable development in Spain", Corporate Social Responsibility and Environmental Management, Vol. 13 No. 2, pp. 78-97.

Garcia, S., Cintra, Y., Torres, Rita de Cássia, S.R. and Lima, F.G. (2016), “Corporate sustainability management: a proposed multi-criteria model to support balanced decision-making", Journal of Cleaner Production, Vol. 136, pp. 181-196.

Gibassier, D. (2015), "The corporate reporting landscape: a market for virtue or the virtue of marketization", Sustainability Accounting, Management and Policy Journal, Vol. 6 No. 4, pp. 527-536.

González González, J.M. (2010), "Determinants of socially responsible corporate behaviours in the Spanish electricity sector”, Social Responsibility Journal, Vol. 6 No. 3, pp. 386-403.

Greiling, D., Traxler, A.A. and Stötzer, S. (2015a), "Sustainability reporting in the Austrian, German and Swiss public sector", International Journal of Public Sector Management, Vol. 28 Nos 4/5, pp. 404-428.

Greiling, D., Grüb, B. and Huber, A. (2015b), "Entwicklungslinien und Ansatzpunkte der Nachhaltigkeitsberichterstattung", Zeitschrift für öffentliche und gemeinwirtschaftliche Unternehmen, Vol. 45, pp. 126-154.

GRI (2015), "G4 Leitlinien zur Nachhaltigkeitsberichterstattung, Berichterstattungsgrundsätze und Standardangaben”, [online], $2^{\text {nd }}$ ed., Deutsche Übersetzung, available at: https://www. globalreporting.org/resourcelibrary/German-G4-Part-One.pdf (accessed 15 October 2017).

Guthrie, J., Petty, R., Yongvanich, K. and Ricceri, F. (2004), "Using content analysis as a research method to inquire into intellectual capital reporting", Journal of Intellectual Capital, Vol. 5 No. 2, pp. 282-293.

Harrison, J.S. (2013), "Stakeholder theory”, in Kessler, E.H. (Ed.), Encyclopedia of Management Theory, Sage Publications, Los Angeles, pp. 763-767.

Herremans, I.M., Nazari, J.A. and Mahmoudian, F. (2016), "Stakeholder relationships, engagement, and sustainability reporting”, Journal of Business Ethics, Vol. 138 No. 3, pp. 417-435.

Higgins, C. and Larrinaga, C. (2014), "Sustainability Reporting. Insights from institutional theory" in Bebbingtion, J., Unerman, J. and O' Dwyer, B. (Eds), Sustainability Accounting and Accountability, Routledge, Oxon and NY, pp. 273-289. 
JPBAFM 32,3
Hörisch, J., Freeman, R.E. and Schaltegger, S. (2014), "Applying stakeholder theory in sustainability management: links, similarities, dissimilarities, and a conceptual framework", Organization and Environment, Vol. 27 No. 4, pp. 328-346.

Islam, M.A. and Deegan, C. (2008), "Motivations for an organisation within a developing country to report social responsibility information: evidence from Bangladesh", Accounting, Auditing and Accountability Journal, Vol. 21 No. 6, pp. 850-874.

Kaur, A. and Lodhia, S. (2018), "Stakeholder engagement in sustainability accounting and reporting: a study of Australian local councils", Accounting, Auditing and Accountability Journal, Vol. 31 No. 1, pp. 338-368.

Kerckhoffs, T. and Wilde-Ramsing, J. (2010), "European works councils and corporate social responsibility in the European energy sector", [online], available at: https://www.somo.nl/wpcontent/uploads/2010/06/European-Works-Councils-and-Corporate-Social-Responsibility-in-theEuropean-Energy-Sector.pdf (accessed 2 November 2017).

KPMG (2017), "The road ahead, the KPMG survey of corporate responsibility reporting 2017", [online], available at: https://home.kpmg.com/xx/en/home/campaigns/2017/10/survey-ofcorporate-responsibility-reporting-2017.html (accessed 1 November 2017).

Kraft, B. (2018), "Shedding light on stakeholder power in a regulated market: a study of variation in electric utilities' climate change disclosures", Organization and Environment, Vol. 31 No. 4, pp. 314-338.

Lock, I. and Seele, P. (2016), "The credibility of CSR (corporate social responsibility) reports in Europe. Evidence from a quantitative content analysis in 11 countries", Journal of Cleaner Production, Vol. 122, pp. 186-200.

Loh, C.M., Deegan, C. and Inglis, R. (2015), "The changing trends of corporate social and environmental disclosure within the Australian gambling industry", Accounting and Finance, Vol. 55 No. 3, pp. 783-823.

Meyer, A. and Pac, G. (2013), "Environmental performance of state-owned and privatized eastern European energy utilities", Energy Economics, Vol. 36, pp. 205-214.

Meyer, J.W. and Rowan, B. (1977), "Institutionalized organizations: formal structure as myth and ceremony", American Journal of Sociology, Vol. 83 No. 2, pp. 340-363.

Miras-Rodríguez, M.D.M., Carrasco-Gallego, A. and Escobar-Pérez, B. (2015), "Has the CSR engagement of electrical companies had an effect on their performance? A closer look at the environment", Business Strategy and the Environment, Vol. 24 No. 8, pp. 819-835.

Mitchell, R.K., Agle, B.R. and Wood, D.J. (1997), "Toward a theory of stakeholder identification and salience: defining the principle of who and what really counts", The Academy of Management Review, Vol. 22 No. 4, pp. 853-886.

Moseñe, J.A., Burritt, R.L., Sanagustín, M.V., Moneva, J.M. and Tingey-Holyoak, J. (2013), "Environmental reporting in the Spanish wind energy sector: an institutional view", Journal of Cleaner Production, Vol. 40, pp. 199-211.

Ng, A.W. and Nathwani, J. (2012), "Sustainability performance disclosures: the case of independent power producers", Renewable and Sustainable Energy Reviews, Vol. 16, No. 4, pp. 1940-1948.

Roca, L.C. and Searcy, C. (2012), "An analysis of indicators disclosed in corporate sustainability reports", Journal of Cleaner Production, Vol. 20 No. 1, pp. 103-118.

Sartori, S., Witjes, S. and Campos, L.M.S. (2017), "Sustainability performance for Brazilian electricity power industry: an assessment integrating social, economic and environmental issues", Energy Policy, Vol. 111, pp. 41-51.

Shabana, K.M., Buchholtz, A.K. and Carroll, A.B. (2017), "The institutionalization of corporate social responsibility reporting", Business and Society, Vol. 56 No. 8, pp. 1107-1135.

Silva-Gao, L. (2012), "The disclosure of environmental capital expenditures: evidence from the electric utility sector in the USA", Corporate Social Responsibility and Environmental Management, Vol. 19 No. 4, pp. 240-252. 
Talbot, D. and Boiral, O. (2018), "GHG reporting and impression management: an assessment of sustainability reports from the energy sector", Journal of Business Ethics, Vol. 147 No. 2, pp. 367-383.

Traxler, A.A. and Greiling, D. (2018), "Sustainable public value reporting of electric utilities", Baltic Journal of Management, [online], available at: https://doi.org/10.1108/BJM-10-2017-0337 (accessed 29 November 2018).

Van der Laan Smith, J., Adhikari, A. and Tondkar, R.H. (2005), "Exploring differences in social disclosures internationally: a stakeholder perspective", Journal of Accounting and Public Policy, Vol. 24 No. 2, pp. 123-151.

Wilmshurst, T.D. (2004), "Stakeholder theory: modelling stakeholder theories as a research tradition:

some Australian evidence", Journal of the Asian Pacific Centre for Environmental Accountability, Vol. 10 No. 3, pp. 3-8.

sustainability reports by electric utilities Accoutability, Vol. 10 No. 3, pp. $3-8$. 
JPBAFM 32,3

\section{8}

\section{Appendix}

Dimensions Performance indicators (PI) and discloser on management Approach(DMA)

Economic Highest coverage: Above $75 \% \quad$ Lowest coverage: Above $25 \%$

EC1 (direct economic value generated and DMA2 (market presence) $23.7 \%$ distributed) $88.7 \%$

DMA8 (plant decommissioning) $22.6 \%$

DMA9 (system efficiency) $18.3 \%$

Ecologic

EN3 (energy consumption within the organization) $82.3 \%$

EN15 (direct greenhouse gas emissions (scope 1)) 89.8\%

EN23 (total weight of waste) $76.3 \%$

Social

Labor practices and decent work

LA1 (total number and rates of new employee hires and turnover) $80.1 \%$

LA6 (type and rates of injury) $89.2 \%$

Human Rights

No indicators above $75 \%$

Society

No indicators above $75 \%$

Table A1.

Highest and lowest coverage rates in SR by EUC

\section{Product responsibility}

No indicators above $75 \%$
EN28 (percentage of products sold and reclaimed packaging materials) $23.7 \%$ DMA18 (transportation) $17.7 \%$

DMA19 (overall) $24.2 \%$

DMA21 (environmental grievance mechanism) $23.7 \%$

DMA29 (labor practices grievance mechanisms) $24.2 \%$

DMA30 (investment) 21\% DMA33 (child labor) 18.8\% DMA34 (forced or compulsory labor) 19.9\% DMA35 (security practices) 15.1\% DMA36 (indigenous rights) $15.1 \%$ DMA37 (assessment) 15.6\% DMA38 (supplier human rights assessment) $24.7 \%$

DMA39 (human rights grievance mechanism) $20.4 \%$

DMA45 (supplier assessment for impact on society) $24.2 \%$

DMA46 (grievance mechanisms for impact on society) $23.1 \%$

DMA50 (marketing) $16.7 \%$

\section{Corresponding author}

Johannes Slacik can be contacted at: johannes.slacik@jku.at

For instructions on how to order reprints of this article, please visit our website: 